\title{
Maternal Age and Length of Work Influencing Breastfeeding Self Efficacy in Primiparous Pregnant Women at Istri Utami Midwifery Care
}

\author{
Siti Nurhidayati ${ }^{1}$, Nurul Kurniati ${ }^{2, *}$ \\ ${ }^{1,2}$ Faculty of Health Sciences, 'Aisyiyah University, West Ringroad 63 Jalan Mlangi Nogotirto Gamping Sleman \\ 55292, Yogyakarta, Indonesia \\ ${ }^{2}$ nurul.kurniati@unisayogya.ac.id* \\ * corresponding author \\ Submission date: 10 Juli 2018, Receipt date: 10 Oktober 2019, Publication date: 1 Juli 2020
}

\begin{abstract}
Nutrition Monitoring in 2016 shows that coverage of exclusive breast milk $54.0 \%$ below the national target of $80 \%$. Breastfeeding self efficacy score measurement to predict mother's belief in giving brest milk. This research aims to know the influence of maternal age and long work with breastfeeding self efficacy This research used survey method with cross sectional approach, population and sample 64 pregnant women in third trimester, primipara both working and not working, sampling using accidental sampling and questionnaire instrument retrieval data using BSE-SF (Breastfeeding Self Efficacy-Short Form) at Istri Utami Midwifery care. The results of the study proved a statistically significant test showing that there was a relationship between age and length of work with Breastfeeding self efficacy in third trimester of pregnant women with p-value $0.022<0.05$ and p-value $0.002<0.05$. Multivariate statistical test results obtained for lenght work has the most significant relationship of these two factors. Length works have smallest value of $p 0.002$ (Exs $\beta=6$,153). Health Technology Assessment (HTA), use of BSE-SF in health service as maternal readiness screening in breastfeeding, support strategy formation in place works to create an environment and time support to increase the duration of breastfeeding in mothers working.
\end{abstract}

Keywords: Maternal age, length of work, occupation, breastfeeding self-efficacy

\section{INTRODUCTION}

Breastfeeding is a strategic way to improve children's health status and basic strategies to help increase children's growth and endurance. In a matter of years breastfeeding is beneficial in the growth and development of children and it also has a good effect on maternal health 1Giving ASI is a method of providing the safest and most healthy baby and contributing in the short and long term to 2The maternal and child health basis for breastfeeding recommendations for breastfeeding can meet the nutritional needs 3 , increased immunity 4 , cognitive improvement and good emotional influence and baby 5 . The program implemented by the government to increase the coverage of exclusive breastfeeding until this year still shows results below the figure targeted by the KEMENKES in 2012 that $80 \%$ of babies are expected to get exclusive breastfeeding from all babies in Indonesia. 
Monitoring of nutritional status in 2016 showed that coverage of infants who received exclusive breastfeeding nationally, namely $54.0 \%$ of infants received exclusive breastfeeding for 5 months and $29.5 \%$ of infants received exclusive breastfeeding for 6 months 4.

According to Dennis (1999) Breastfeeding Self-Efficacy is a mother's selfconfidence in her ability to breastfeed her child, which is influenced by her decision to breastfeed, especially to give breast milk or not, how much effort to breastfeed and how to deal with problems in case during breastfeeding. Mothers with a high BSE score are more likely to give exclusive breastfeeding, to survive when they have difficulty when breastfeeding, to empower themselves during the breastfeeding process and always think positively when getting problems while breastfeeding 5 .

BSE Effective in measuring mother's breastfeeding ability, improvement / improvement Breastfeeding self efficacy is straight-line with the duration of breastfeeding, especially in providing exclusive breastfeeding and breastfeeding quality of life 6,7. Vincent's (2015) study explained that the group given the intervention in the breastfeeding class showed a significant increase in ASI after being measured by a Brief Form of Breastfeeding Self-Efficacy Scale (BSES-SF) 8. Mandiri Practical Midwife Istri Utami is a service provider midwife in Sleman district. At the time of observation, mothers who had postpartum control found 3 mothers from 5 mothers who gave birth in 1 week normally that the mother felt the need for additional formula milk or just plain water because her milk had not come out. 3 of the mothers 2 of them came out but few and 1 mother did not come out yet. This preparation can be optimized when the mother goes through the pregnancy process. The number of pregnant patients in 2017 reached 529 pregnant women. so researchers are interested in doing research on the influence of maternal characteristics on breastfeeding self efficacy in pregnant women, especially in the third trimester of Wife's Utami PMB.

\section{RESEARCH METHODS}

This research is a quantitative research, while the design used is a survey method with a cross sectional approach. The population of this study were third trimester primiparous pregnant women

\section{RESULTS AND DISCUSSION}

\section{Characteristics of Respondents}

Table 1 characteristics of research respondents during May-June 2018 as many as 65 people. The sample of this study used Accidental sampling technique, all primiparous pregnant women with gestational age $\geq 28$ weeks without complications . Data collection method uses BSE-SF questionnaire in Indonesian language . In the same study, Cronbach's alpha coefficient for internal consistency was 0.87 antenatal and 0.86 postnatal (Nursan et, al , 2014). Canadian studies in 491 breastfeeding mothers found that BSES-SF is a valid instrument that is a value of 0.96 to measure the risk of termination of breastfeeding by nursing mothers (Dennis, 2003). In Indonesia in Wardani's (2012) study, the BSES-SF instrument that was translated was tested with a reliability value of 0.872 . Univariate analysis was carried out with descriptive statistics to describe the characteristics of the research variables. Bivariate analysis using chisqure to determine the relationship of two variables with a $95 \%$ confidence level with $p$ 
$=0.05$. Then multivariate analysis to find out the most influential variables on breastfeeding self efficacy.

Table 1. Characteristics of Research Respondents

\begin{tabular}{|c|c|c|}
\hline Characteristics & Frequency $(\mathrm{F})$ & Percentage (P) \\
\hline \multicolumn{3}{|l|}{ Age } \\
\hline$<20$ years & 24 & $37.50 \%$ \\
\hline$\geq 20$ years & 40 & $62.50 \%$ \\
\hline \multicolumn{3}{|l|}{ Education } \\
\hline Low & 13 & 20.3 \\
\hline High & 51 & 79.7 \\
\hline \multicolumn{3}{|l|}{ Income } \\
\hline$<$ UMR & 38 & 59.4 \\
\hline R UMR & 26 & 40.6 \\
\hline \multicolumn{3}{|l|}{ The desire to breastfeed } \\
\hline Formula & 4 & 6.3 \\
\hline Partial & 13 & 20.3 \\
\hline Exclusive & 47 & 73.4 \\
\hline \multicolumn{3}{|l|}{ Length of work } \\
\hline Full time & 45 & 70.3 \\
\hline Part time & 19 & 29.7 \\
\hline \multicolumn{3}{|l|}{ BSE-S F } \\
\hline Less & 27 & 42.2 \\
\hline Good & 37 & 57.8 \\
\hline Amount & 64 & 100 \\
\hline
\end{tabular}

Table 1 univariate analysis shows that most respondents aged $\geq 20$ years amounted to 40 people $(62.5 \%)$, highly educated (SMA and PT) as many as 51 people $(79.7 \%)$, income $\geq$ UMR (IDR 1,200,000) amounting to 26 people $(40.6 \%$ ). Of the 64 pregnant women most of them had the desire to provide exclusive breastfeeding as many as 47 people (7 3.4\%), working full time ( $>7$ hours per day ) totaling 45 people $(70.3 \%)$ and more who had good faith (BSE-SF) totaling 37 people (57.8\%).

Table 2. bivariate analysis of maternal age with breastfeeding self efficacy

\begin{tabular}{|c|c|c|c|c|c|c|c|c|}
\hline \multirow{3}{*}{ Age } & \multicolumn{4}{|c|}{ BSE-SF } & \multirow{2}{*}{\multicolumn{2}{|c|}{ Total }} & \multirow{3}{*}{$P$-value } & \multirow{3}{*}{$\mathbf{C}$} \\
\hline & \multicolumn{2}{|c|}{ Less } & \multicolumn{2}{|c|}{ Good } & & & & \\
\hline & f & $\%$ & f & $\%$ & f & $\%$ & & \\
\hline$<20$ years & 15 & 23.4 & 9 & 14.1 & 24 & 37.5 & & \\
\hline$\geq 20$ years & 12 & 18.8 & 28 & 43.7 & 40 & 62.5 & 0.022 & 0.304 \\
\hline Total & 27 & 42.2 & 37 & 57.8 & 64 & 100 & & \\
\hline
\end{tabular}

Based on table. 2 the bivariate analysis shows that more respondents aged $<20$ years who have BSE-SF scores are less confident as many as 15 respondents $(23.4 \%)$ compared to the BSE-SF score of good self confidence as many as 9 respondents 
(14.1\%) . While respondents aged $\geq 20$ years were more likely to have good BSE-SF scores $(43.7 \%)$ than those with less scores (18.8\%). Chi-Square test results are p-value showsthe results of 0.022 , so it can be concluded that p-values $0.022<0.05$ and there is a relationship of age with Breastfeeding self efficacy in primiparous mothers in PMB Istri Utami Sleman . Contingency coefficient value shows that $C=0.304$, which means the strength of the relationship of the contingency coefficient is low $(0.20-0.399)$.

Table 3. bivariate analysis of maternal age with breastfeeding self efficacy

\begin{tabular}{ccccccccc}
\hline \multirow{2}{*}{$\begin{array}{c}\text { Length of } \\
\text { work }\end{array}$} & \multicolumn{9}{c}{ Less } & \multicolumn{3}{c}{ good } & & \multirow{2}{*}{ Total } & \multirow{2}{*}{ P-value } & C \\
\cline { 2 - 7 } & f & \% & f & \% & f & \% & & \\
\hline Full time & 14 & 21.9 & 5 & 7,8 & 19 & 29.7 & & \\
Part time & 13 & 20.3 & 32 & 50 & 45 & 70.3 & 0.002 & 0.383 \\
Total & 27 & 42.2 & 37 & 57.8 & 85 & 100 & & \\
\hline
\end{tabular}

Based on Table 3, a bivariate analysis showed that mothers who worked full time had more BSE-SF who lacked confidence (21.9\%) than had a confident BSE-SF score $(7.8 \%)$. Whereas mothers who work part-time tend to have a BSE-SF score of good confidence $(50.0 \%)$ compared to a BSE-SF score less confident $(20.3 \%)$. The results of the Chi- Squere test that is p-value shows $0.002<0.05$ and there is a long relationship to work with Breastfeeding self efficacy in primiparous mothers in PMB Istri Utami Sleman. Contingency coefficient value shows that $\mathrm{C}=0.383$, which means the strength of the relationship of the contingency coefficient is low (0.20-0.399).

Table 2 multivariate analysis of maternal age with breastfeeding self efficacy

\begin{tabular}{ccc}
\hline Variable & p (value) & Exp $\boldsymbol{\beta}$ \\
\hline Age & 0.04 & 3,358 \\
Length of work & 0.004 & 6,153 \\
\hline
\end{tabular}

Based on table. 4 multivariate analysis showed that the two variables studied, both had a significant relationship with breastfeeding self efficacy, because these two variables had $\mathrm{p}$ value $<0.05$. Age has a value of $\mathrm{p}$ value 0.040 and $\operatorname{Exp} \beta 3.358$, and husband's support has a $\mathrm{p}$ value of 0.004 and $\operatorname{Exp} \beta$ 6.153. From these two variables, the working time variable has the smallest $\mathrm{p}$ value of 0.004 , so it can be concluded that working time is a variable that has the most significant relationship with breastfeeding self efficacy, and has Exp $\beta 6.153$ so that mothers who work part time have six opportunities times bigger for confidence well compared to mothers who work full time.

Self efficacy is someone's belief to be able to succeed in certain situations. This affective characteristic is one of the strongest predictors of various behaviors including breastfeeding ${ }^{9}$. Breastfeeding self efficacy is able to measure maternal initiation for breastfeeding, breastfeeding behavior over time ${ }^{10}$. The high BSE-SF score is in a straight line with an increase in the duration of breastfeeding and the success of exclusive breastfeeding ${ }^{11.12}$.

The characteristics of the mothers studied focused on the age and length of work of the mother, the age of the mother obtained from the age at the time of the study and the length of work obtained from the estimated working time of the mother in 24 hours both working in the office and working independently at home. The results of data analysis showed that mothers aged $\geq 20$ years had good self confidence shown by the BSE-SF score of 28 people (43.7\%). The chi-square test results showed a significant relationship between age and breastf eeding self 
efficacy in third trimester pregnant women ( $\mathrm{p}$-value $=0.022, \alpha=95 \%$ ). Contingency kiofisien value shows that $\mathrm{C}=0.304$ which has a low relationship value 90.20-0.399).

Age is the age of the mother at the time of data collection. Age is classified as 2 ie $<20$ years and dan 20 years. In this study stated that mothers aged $\geq 20$ years had a good score of Breastfeeding Self Efficacy, age was related to BSE-SF score. Characteristics of maternal age have been discussed in previous studies that maternal age affects the score of breastfeeding self efficacy in the plan for breastfeeding ${ }^{13.14}$.

Age affects emotional maturity in one's decision making. Maternal confidence in breastfeeding is closely related to emotional readiness and the incidence of depression in the mother. Mothers who are pregnant and give birth aged $<25$ years have a risk of weaning their children less than weaning their children $<6$ months ${ }^{15}$. Mother's age directly influences mental mastery and environmental mastery which has the effect of a sense of self-acceptance interaction to autonomously determine who can breastfeed his child to a maximum of ${ }^{16}$. So that in this case the support of the family and the environment, identification of signs of depression and the addition of information while pregnant is needed especially for mothers aged $<20$ years ${ }^{15}$. The results of data analysis show that respondents who work part-time have good self-confidence as many as 32 respondents $(50.0 \%)$. The chi-square test results showed a significant relationship between the duration of work with breastfeeding self efficacy of pregnant women $\mathrm{TM}^{2}$ (p-value $=0.002, \alpha=95 \%$ ). Contingency kiofisien value shows that $\mathrm{C}=$ 0.304 which has a low relationship value 90.20-0.399).

Long working is a criterion for the duration of the mother's work in hours, the calculation is done with a limit of 7 hours per day. Mother's working time is classified into full time and part time. In this study stated that mothers who work part-time are more confident that they can provide breastfeeding exclusively. Mothers who have full-time jobs have low confidence in giving exclusive breastfeeding 6 months ${ }^{16}$. Some reasons for working mothers who do not provide exclusive breastfeeding such as the feeling of laziness from the mother, the demands of a high workload, little leave time, lack of infrastructure so that mothers prefer not to exclusively breastfeed. Most mothers give breast milk only 1 month and then breastfeeding is mixed or replaced with formula milk ${ }^{17}$. The duration of work of a mother is included in the workload associated with self efficacy, the heavier the workload will reduce a person's confidence in giving exclusive breastfeeding ${ }^{18}$. The results of multivariate analysis showed that working duration variables had the most significant relationship with breastfeeding self efficacy $\operatorname{Exp} \beta=6.153$ so that mothers who work part time have a 6 times greater chance of having good confidence in breastfeeding than those who work full time. Self-efficacy is a predictor for the duration of breastfeeding. workplaces can help improve breastfeeding self efficacy in mothers by providing a supportive environment and giving time for exclusive breastfeeding ${ }^{19}$. Confidence in breastfeeding mothers also need support from families, groups of ASI and health care workers ${ }^{20 .}$

\section{CONCLUSION}

Based on the results of the study of age and length of work have a significant relationship with increased self-confidence in breastfeeding in pregnant women in third trimester in the wife Utami PMB. so mothers who have age $\geq 20$ years tend to be more confident to give breast milk after giving birth. Then the mother who works part-time is also more confident that she can make time to be able to breastfeed her child even though she works. part-time working mothers have six times more confidence in being able to breastfeed after giving birth than mothers who work full time. The provision of maternity leave and the time to take care of their children can be used as a strategy to increase the coverage of exclusive breastfeeding, especially for working mothers. 


\section{REFERENCES}

A Hatami and Z.Talebi. 2007. Patterns of Breastfeeding in infans". Persian : HayatVictora, C. G., Bahl, R., Barros, A. J. D., França, G.V. A., Horton, S., Krasevec, J., ... Rollins, N. C.(2016). Breastfeeding in the 21st century: epidemiology, mechanisms, and lifelong effect. The Lancet, 387(10017), 475490. doi:10.1016/s0140-6736(15)01024-7

Jedrychowski W; Perera F;Jankowski J; Butscher M; Mroz E; Flak E; Kaim I; Miszczyk IL; Skarupa A; Sowa A. (2012). Effect of Exclusive Breastfeeding on the Development of Children's Cognitive Function in the Krakow Prospective Birth Cohort Study. Eur J Pediatr 2012 January ; 171(1): 151-158. doi:10.1007/s00431-011-1507-5

Badan Pusat Statistik dan makro international. 2012. Survey Demografi dan Kesehatan Indonesia Tahun 2012. Badan Pusat Statistik dan makro international, Calverton, Martland, USA

Yi Chan M., Yim IW and Cow Choi K. 2016. The Effect of a self efficacy based Educational Program on Maternal Breast Feeding Self-efficacy Breastfeeding Duration and Exclusive Breastfeeding rates : A longitudinal Study".Scient Direct : Hongkong

Brockway M., Benzies K and Hayden KA. 2017. Interventions to improve Breastfeeding Self-efficay and Resultant Breastfeeding Rate : A Systematic Review. Journal Human Lactation : Canada

Mirghafourvand, M., Kamalifard, M., Ranjbar, F., \& Gordani, N. (2017). Relationship of breastfeeding self-efficacy with quality of life in Iranian breastfeeding mothers. The Journal of Maternal-Fetal \& Neonatal Medicine, 31(20), 27212728. doi:10.1080/14767058.2017.1354368

Vincent, A. (2015). The Effect of Breastfeeding Self-Efficacy on Breastfeeding Initiation, Exclusivity and Duration.

Bandura A. Self-efficacy: toward a unifying theory of behavioral change. Psychol Rev .. 1977; 84(2): 191-215.[PubMed: 847061]

Labbok MH. Breastfeeding: population-based perspectives. Pediatr Clin North Am .. 2013; 60(1): 11-30. [PubMed: 23178058]

Varei Sh, Mehrdad N, Bohrani N. The relation between breastfeeding self efficacy and position of breastfeeding in mothers. J Fac Nurs Midwif.; 2009;15:31-38

Faridvand F, Mirghafourvand M, Malacouti j, et al. Predictors of breastfeeding selfefficacy in Iranian women: A cross-sectional study. Int J Women's Health Reprod Sci. 2017;5.

Zubaran C, Foresti K, Schumacher MV,Amoretti All,Muller LC, et.al. The Portugese Version of the Breastfeeding Self-Efficacy Scale-Short Form. J Hum Lact 2010 ; 26: 297-303

Oria MO, Ximene LB, de Akmeida OC,Glick DF, Dennis CL. Psychometric Assesment of the Brazilian Version of the Breastfeeding Self Efficacy Scale. Public Health Nurs 2009; $30: 244-54$.

Kehler HI, Chaput KH, ToughSC. Risk Factor for Cessation of Breastfeeding prior to six Months Postpartum among a community sample of women in Calgary. Alberta Can J Public Health 2009100; 376-380

Lawal, A. M., \& Idemudia, E. S. (2017). Examining maternal age, breastfeeding selfefficacy and health locus of control in psychological wellbeing of mothers. 
Psychology, Health \& Medicine, 22(10), 1230-1238. doi:10.1080/13548506.2017.1317824

Haryani. (2014). Alasan Tidak Diberikan ASI Eksklusif oleh Ibu Bekerja di Kota Mataram Nusa Tenggara Barat.

Kusnadi MA. (2014). Hubungan antara Beban Kerja dan Self Efficacy dengan Stres Kerja pada Dosen Universitas X. Jurnal Ilmiah Mahasiswa Universitas Surabaya ; Surabaya

Wallenborn, J. T., Perera, R. A., Wheeler, D. C., Lu, J., \& Masho, S. W. (2018). Workplace support and breastfeeding duration: The mediating effect of breastfeeding intention and self-efficacy. Birth. doi:10.1111/birt.12377

Pounds, L., Fisher, C. M., Barnes-Josiah, D., Coleman, J. D., \& Lefebvre, R. C. (2017). The Role of Early Maternal Support in Balancing Full-Time Work and Infant Exclusive Breastfeeding: A Qualitative Study. Breastfeeding Medicine, 12(1), 33-38. doi:10.1089/bfm.2016.0151 